\title{
Numerical Simulation of Rock Uniaxial Compressive Strength and Deformation Failure Law under Different Size Conditions
}

\author{
Zhichao Tian $\left(D,{ }^{1,2}\right.$ Chunan Tang, ${ }^{1,3}$ Hao Li, ${ }^{2}$ Hui Xing, ${ }^{4}$ and Xiangda Ning ${ }^{2}$ \\ ${ }^{1}$ School of Resources and Civil Engineering, Northeastern University, Shenyang, Liaoning 110819, China \\ ${ }^{2}$ School of Civil Engineering, Inner Mongolia University of Science and Technology, Baotou, Mongolia 014010, China \\ ${ }^{3}$ Dalian University of Technology, Dalian, Liaoning 116024, China \\ ${ }^{4}$ Institute of Mining Research, Inner Mongolia University of Science and Technology, Baotou, Mongolia 014010, China \\ Correspondence should be addressed to Zhichao Tian; bailey280@163.com
}

Received 13 October 2020; Revised 30 November 2020; Accepted 19 December 2020; Published 15 January 2021

Academic Editor: Hualei Zhang

Copyright ( $\odot 2021$ Zhichao Tian et al. This is an open access article distributed under the Creative Commons Attribution License, which permits unrestricted use, distribution, and reproduction in any medium, provided the original work is properly cited.

\begin{abstract}
Rock engineering occupies an important position in the 21st century. In the face of rock engineering disasters, we are only looking for the essential problems through experiments on rocks, but rock experiments cannot be realized in large numbers, so the article uses numerical simulation software RFPA (Realistic Failure Process Analysis) 2D Basic to simulate rock under different size conditions numerically. In this paper, a rock model with a diameter of $50 \mathrm{~mm}$ is used for simulation research. Meanwhile, five calculation models of height-to-diameter ratios of 1.0, 1.5, 2.0, 2.5, and 3 are used. Through simulation calculation, we find that the rock model failure is more than complicated when the value of the height-to-diameter ratio is exceedingly low (1), but as the height-to-diameter ratio increases, the failure mode will become simpler. The stress-concentrated failure will be in the form of axial failure. When the height-to-diameter ratio increases (1.5-2), other damage cracks appear on the basis of axial cleavage failure. As the height-to-diameter ratio continues to increase (about 2.5), only shear failure occurs. When the height-to-diameter ratio reaches a relatively high level (3), there will be both axial rip and other damage. When the height-to-diameter ratio is oversize, there will be both axial rip failure and end damage.
\end{abstract}

\section{Introduction}

With the advancement of science and technology, in order to meet human needs for resources and production space, the development scale of underground space is getting larger and the depth is getting deeper; besides, the problems of rock engineering encountered are becoming more and more complicated. Therefore, further comprehensive exploration of the contents of rock geological characteristics, physical properties, mechanical properties, and other aspects has become a problem to be solved urgently [1-3].

In the 21st century, rock engineering occupies an important position. For a long time, people have done a lot of researches on the strength characteristics of rocks, hoping to get an ideal rock where stress, strain, loading, and so on can meet certain laws, and at the same time, a variety of theories have been proposed, such as Mohr-Coulomb, Double-
Shear, Hoek-Brown, and Single-Shear [4-7], but the above theories are the conclusions which are based on rock physics experiments, because physical experiments require a large number of test pieces, time, and funds. It causes a phenomenon that many scholars draw conclusions with doing only a few tests when they do physical experiments. Their conclusions have certain limitations. Consequently, based on the limitations of physical experiments, the finite element software RFPA2D is used to simulate the strength failure and acoustic emission of rock $[8,9]$.

\section{Introduction and Modeling of RFPA2D Basic}

2.1. Introduction to RFPA (Realistic Failure Process Analysis). RFPA (Realistic Failure Process Analysis) is an analysis program of rock instability process. This program is developed based on the principle of finite element calculation 
[10-13], but it is different from the traditional basic idea of finite element. It is mainly used to study the whole process of rock mass material from mesodamage to macroscopic failure. The basic principles are as follows:

(1) Simulate the nonlinearity of rock deformation and failure by considering the heterogeneous microstructure of the rock

(2) Simulate the discontinuity of rock deformation and fracture by weakening of material properties after unit failure [14]

The RFPA software mainly simulates the failure process of brittle media, and it uses the degree of homogeneity $(m)$ to describe the heterogeneity of brittle media, which is in line with the destruction nature of brittle rock masses. The acoustic emission energy of the whole process of brittle rock mass destruction can be continuously simulated and displayed, which can realize the comparative analysis of acoustic emission characteristics of brittle rock masses of various sizes [15]. Therefore, the RFPA software is chosen to study the failure mechanism of uniaxially compressing rocks under different loading rates.

\subsection{Rock Mechanical Parameters and Model Simplification.} In order to fully show the rock failure law and the contrastive characteristics of deformation failure with the change of size, the mechanical parameters of marble are used for calculation to simulate the fracture morphology and stress-strain of rock in the process of uniaxial compression failure. We adopt a rock model whose diameter is equal to $50 \mathrm{~mm}$. In addition, five calculation models of height-to-diameter ratios of 1.0, $1.5,2.0,2.5$, and 3 are used. Because the influence of different size on rock stress is studied in this paper, the influence of rock type on its simulation results is ignored.

The choice of the ratio of height to diameter of rock is based on the standard specimen requirements of compression test in material mechanics. According to the standard specimen requirements, the model reduces the influence of its stability on the strength [16]. Because the numerical simulation software is two-dimensional, therefore, the plane stress calculation model is used in the calculation of the model.

2.2.1. Relevant Parameters of Calculation Model Mechanics. Rock failure is determined by the Mohr-Coulomb strength criterion [17]. The control parameters of the phase change criterion are shown in Table 1 , and the mechanical parameters of the model body are shown in Table 2 .

2.2.2. Grid Division and Loading of Calculation Model. A model with a diameter of $50 \mathrm{~mm}$ and height-to-diameter ratios of $1,1.5,2,2.5$, and 3 was established for size effect analysis, as shown in Table 3. The loading method was uniaxial compression, as shown in Figure 1; besides, in order to enhance accuracy of calculation, the grid is divided into a range of 40,000 to 60,000 , as shown in Figure 2. In order to faithfully reproduce the failure state of the model test piece
TABle 1: Phase change criterion control parameters.

\begin{tabular}{lc}
\hline Control parameter & Parameter value \\
\hline The compressive strength-tensile strength ratio & 0 \\
Residual strength coefficient & 0.1 \\
Phase transition criterion & 1.5 \\
Maximum tensile strain coefficient & 200 \\
Maximum compressive strain coefficient & \\
Mohr-Coulomb strength criterion & \\
\hline
\end{tabular}

TABLE 2: Rock material properties.

\begin{tabular}{lccc}
\hline & $\begin{array}{c}\text { Elastic Modulus } \\
(\mathrm{MPa})\end{array}$ & $\begin{array}{c}\text { Poisson } \\
\text { ratio }\end{array}$ & Density $\left(\mathrm{kg} / \mathrm{m}^{3}\right)$ \\
\hline Homogeneity & 10 & 100 & 100 \\
Average value & 50000 & 0.25 & 2500 \\
\hline
\end{tabular}

in the physical test, displacement loading is chosen as the loading method of the model, as shown in Figure 3.

\section{Numerical Simulation Calculation Results of Rocks under Different Size Conditions}

3.1. Simulation Results of Macroscopic Failure of Model under Different Height-to-Diameter Ratio. Figures 4(a)-4(d) show the macroscopic failure of the model when the height diameter ratio is 1 , in which (a) is the initial stress state calculated by the model and (d) is the final macroscopic failure of the model. At the beginning of model calculation, Figures 4(a) and 4(b) show the compaction stage of the model. With the increase of calculation steps, the model is compacted to a certain extent, and there are microcracks in Figures 4(b) and 4(c) and the microcracks of the model expand along the model $45^{\circ}$. In addition, cracks appear at the bottom of the model, resulting in stress concentration at the bottom of the model. Therefore, many cracks appear at the bottom of the model along the axial direction of $45^{\circ}$, as shown in Figure $4(\mathrm{~d})$. With the increase of displacement loading and calculation step, the $45^{\circ}$ crack continued to expand, and the main crack was formed rapidly. The macroscopic failure mode of the model is more complex, which is mainly manifested as multiple cracks appearing along the $45^{\circ}$ axis of the longitudinal shear plane and end failure appearing at the bottom.

Figures 5(a)-5(d) show the macroscopic damage of the model at ratio of height to diameter of 1.5. At the beginning of model calculation, Figures 5(a) and 5(b) represent the model compaction stage; with the increase of the calculation step, the model is compacted to a certain extent. There are tiny cracks in Figure 5(c), which expands along the $45^{\circ}$ direction. At the same time, due to the emergence of cracks, stress concentration phenomenon appears in the middle of the model. Therefore, two intersecting cracks emerge along the $45^{\circ}$ axis direction with the center of stress concentration, as shown in Figure 5(c). With the loading of displacement and the increase of calculation step, the $45^{\circ}$ crack continues to expand, and the main crack gradually forms from the stress concentration area to the outside. The failure mode of 
TABLE 3: Size effect model information.

\begin{tabular}{lcccc}
\hline Model number & Model name & Model size $(\mathrm{mm})$ & Load $(\mathrm{mm} / \mathrm{step})$ & Height-to-diameter ratio \\
\hline 1 & Marble & $50 \times 50$ & 0.000002 & 1.0 \\
2 & Marble & $50 \times 75$ & 0.000002 & 1.5 \\
3 & Marble & $50 \times 100$ & 0.000002 & 2.0 \\
4 & Marble & $50 \times 125$ & 0.000002 & 2.5 \\
5 & Marble & $0 \times 150$ & 0.000002 & 3.0 \\
\hline
\end{tabular}

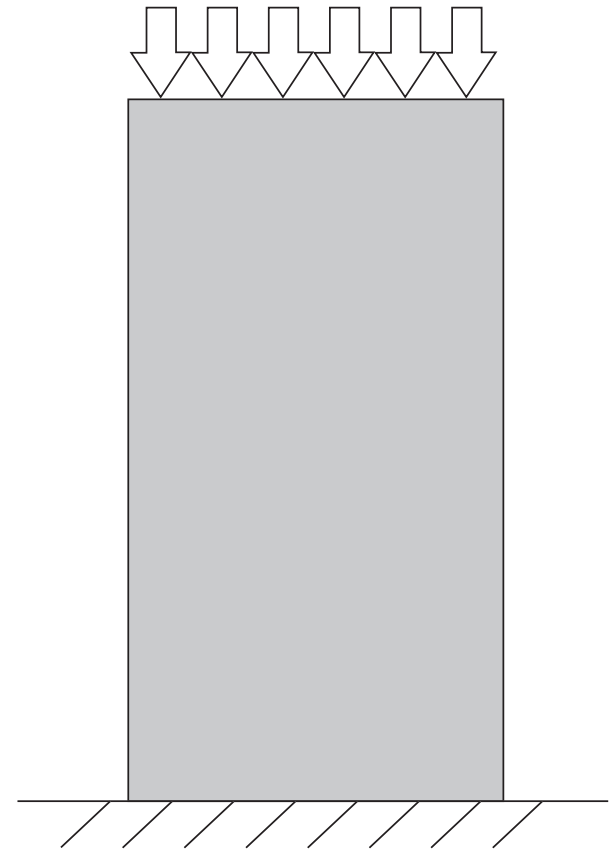

Figure 1: Model load diagram.

the model is relatively simple, mainly showing that two longitudinal splitting surfaces appear along the $45^{\circ}$ axis.

Figures 6(a)-6(d) show the macroscopic damage condition of the model at ratio of height-to-diameter of 2, where Figure 6(a) is the initial stress state calculated by the model, and figure $(f)$ is the final macroscopic damage of the model. At the initial stage of model calculation, Figure 6(a) and 6(b) are the compaction stage of the model. With the increase of the calculation step, tiny cracks appear as Figure 6(b) shows when the model is compacted to a certain extent, and the tiny cracks of the model are extending along $45^{\circ}$ direction of the model. Meanwhile, stress concentration phenomenon appears in the middle of the model due to the appearance of cracks. Therefore, the model presents a phenomenon that two cracks appear along the $45^{\circ}$ axial direction based on middle part where the stress concentrates, as shown in step 5(c) of Figure 6. As the process of displacement loading and the increases of calculation steps, the $45^{\circ}$ crack continues to grow, and the main crack gradually forms in the process of extending from the stress concentration area to external part. The model failure mode is relatively simple, mainly manifested as two longitudinal shear failure cracks appearing along the $45^{\circ}$ axial direction.

Figure 7(a) to Figure 7(d) show the macroscopic failure of the model when the height diameter ratio is 2.5 , in which (a) is the initial stress state calculated by the model and (d) is the final macroscopic failure of the model. At the beginning

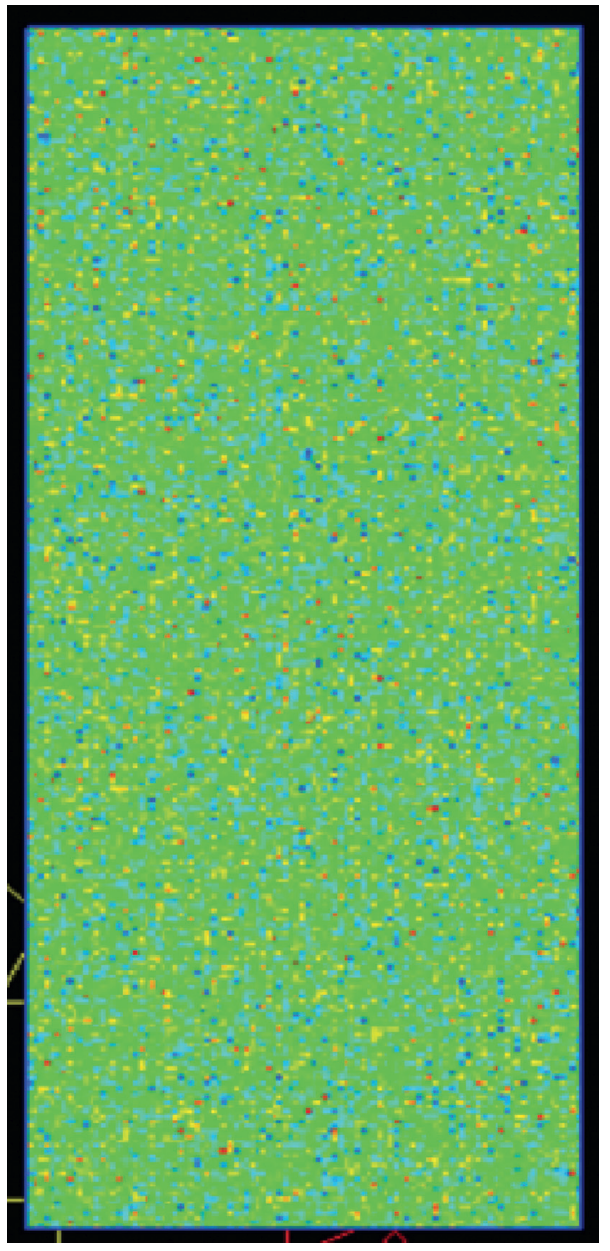

FIgURe 2: Model meshing diagram.

of model calculation, Figure 7(a) and 7(b) show the compaction stage of the model. With the increase of calculation steps, the model is compacted to a certain extent, and there are microcracks in Figure 7(b) and 7(c), and the microcracks of the model expand along the model $45^{\circ}$. Because the appearance of cracks causes stress concentration in the middle of the model, one crack appeared along the $45^{\circ}$ axis based on the middle part of the model, as shown in Figure 7(c). With the displacement loading and the increase of calculation steps, the $45^{\circ}$ crack continues to expand, and the main crack gradually forms from the stress concentration area. The failure mode of the model is relatively simple, which mainly shows a shear failure crack along the axis of $45^{\circ}$ in the longitudinal direction.

Figure 8(a) to Figure 8(d) show macroscopic destruction process of the model at ratio of height to diameter of 3 , 


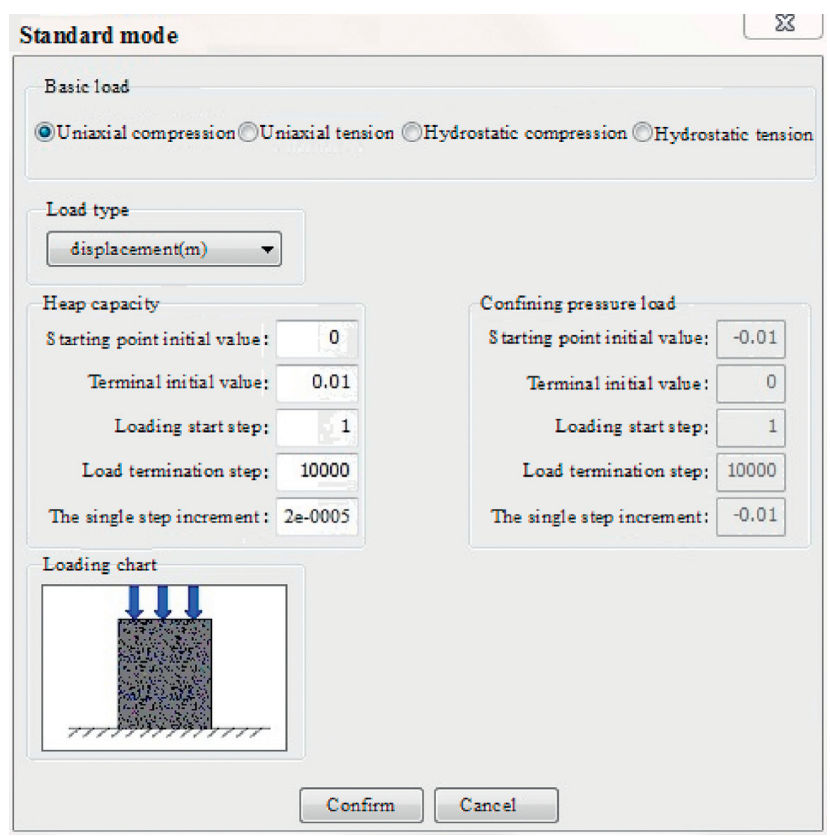

FIGURE 3: Model displacement loading method.

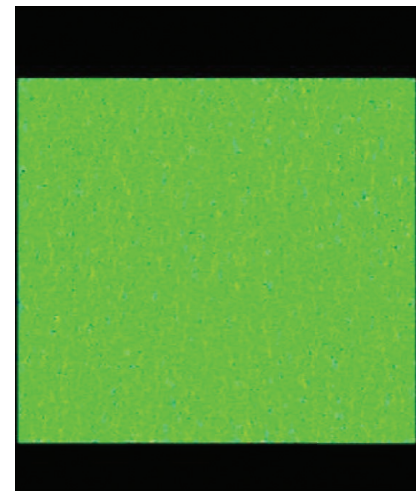

(a)

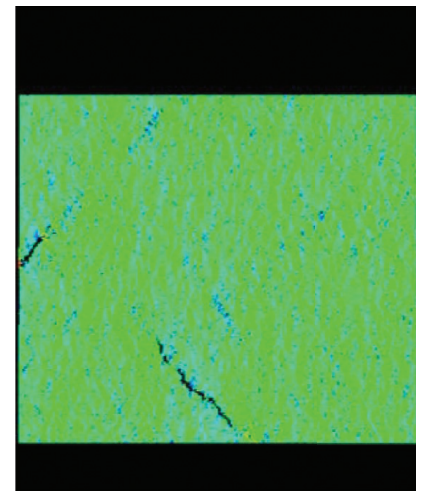

(b)

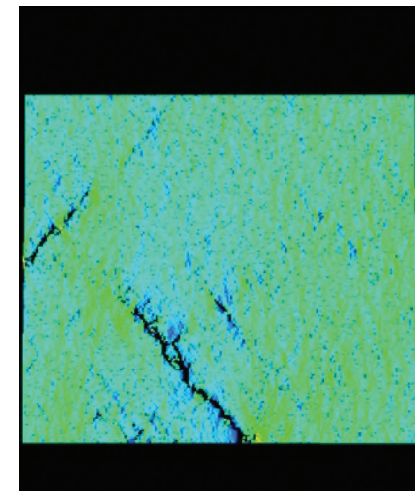

(c)

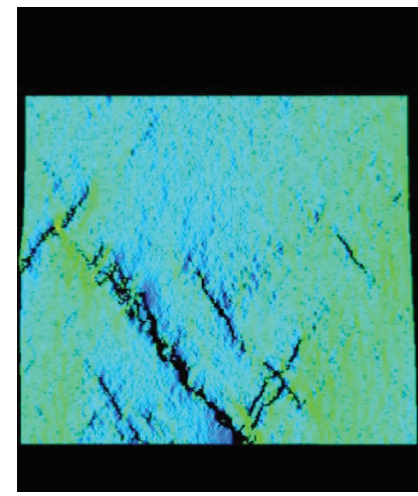

(d)

Figure 4: Macrodestruction of rock mass at ratio of height to diameter of 1 .

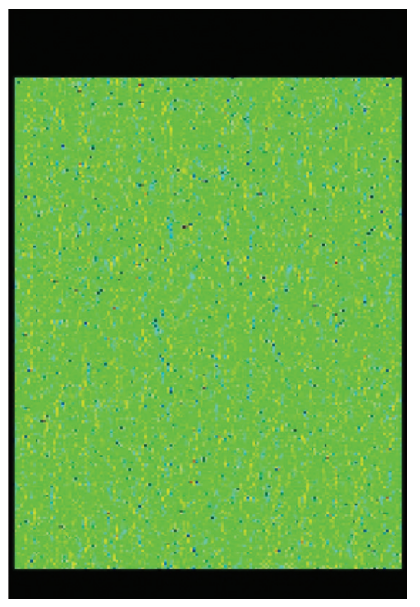

(a)

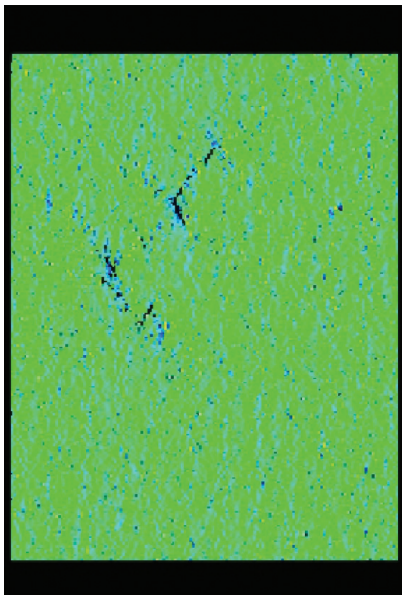

(b)

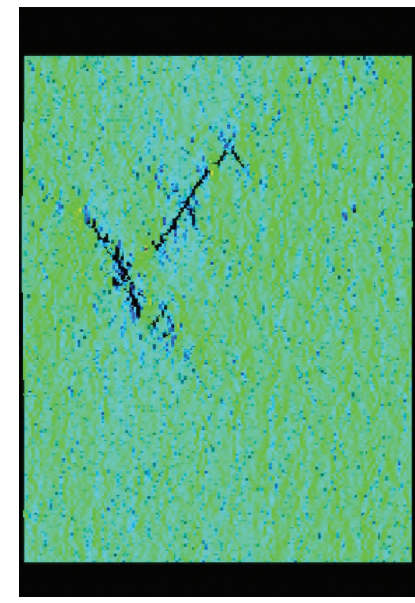

(c)

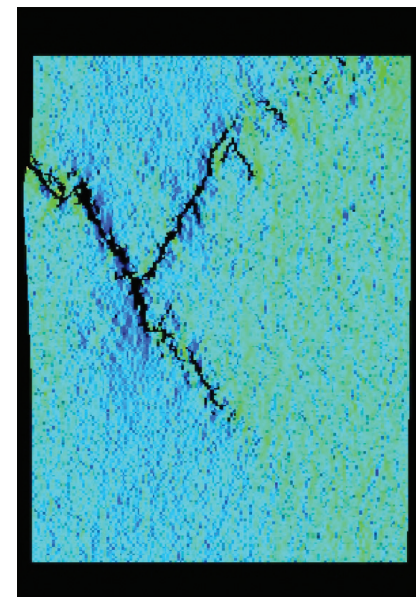

(d)

FIgURE 5: Macroscopic failure of rock mass when the ratio of height to diameter is equal to 1.5. 


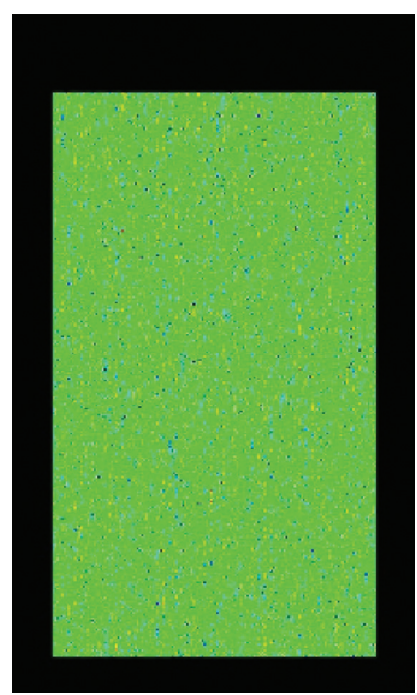

(a)

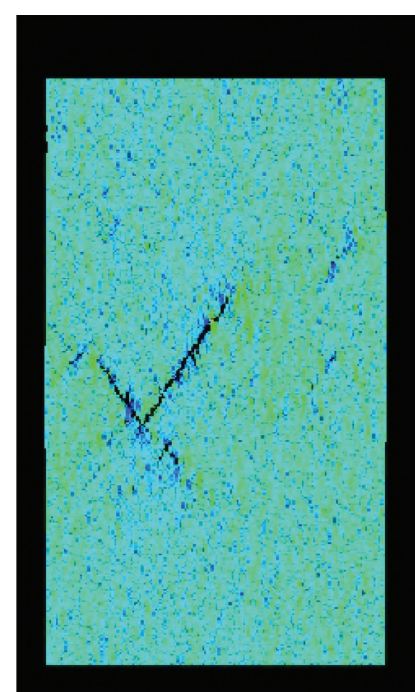

(b)

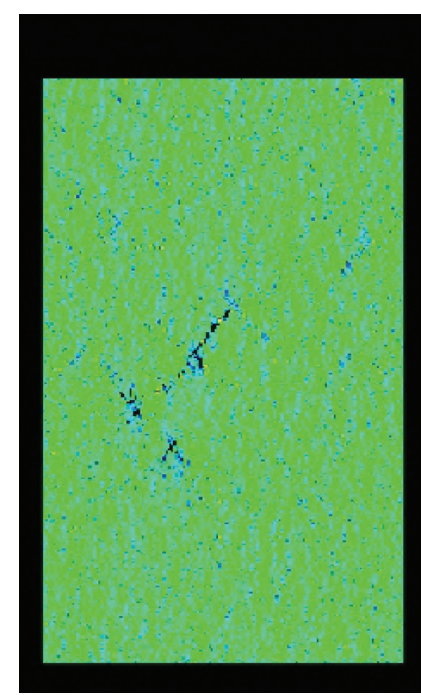

(c)

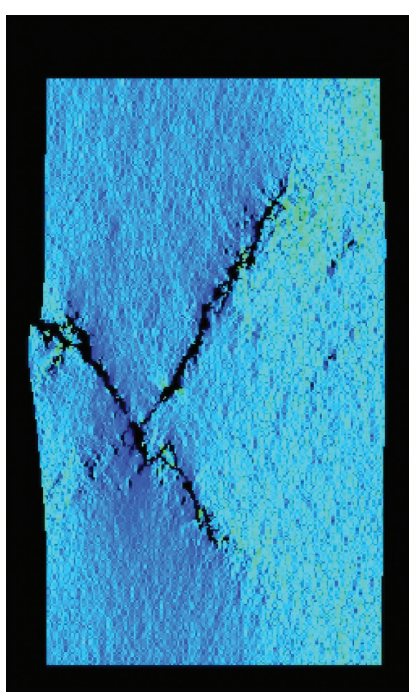

(d)

FIGURE 6: Macroscopic failure of rock mass at the height-to-diameter ratio of 2.

where Figure $8(a)$ is the initial stress state calculated by the model, while Figure 8(d) is the final macroscopic destruction of the model. At the initial stage of model calculation, Figure $8(\mathrm{a})$ to Figure $8(\mathrm{~b})$ are the compaction stage of the model; with the increase of the calculation step, the model is compacted to a certain extent, and microcracks appear in Figure 8(b) and Figure 8(c). Besides, the microcracks of the model spread along $45^{\circ}$ direction of the model. At the same time, stress concentration phenomenon occurs in the lower middle part of the model due to the appearance of cracks. Therefore, the model presents a phenomenon that one biggish crack and one lesser crack appear along the $45^{\circ}$ axial direction based on middle part where the stress concentrates, as shown in step 5(c) of Figure 8. As the displacement loading progresses and the calculation step increases, the $45^{\circ}$ crack continues to extend, and the expansion accelerates to form the main crack. A lesser crack appears on the basis of the main crack. The failure mode of the model is relatively simple, mainly manifested as a main crack formed by $45^{\circ}$ shear failure along the surface, and there is a lesser crack that intersects the main crack and extends at an axial $45^{\circ}$.

In summary, as shown in Figures 4-8, through comprehensive and comparative analysis, it is found that, with the increase of the height-to-diameter ratio, the failure mode of the model changes from complex to simple, and the dominant number of cracks changes from 2-4 to 1-2. When the height-to-diameter ratio is equal to 3.0 , the damage degree of the model is the lowest, and the failure force and consumed time are the least, indicating that, in addition to the influence of strength, the stability of the model also affects the failure mode of the strength value.

3.2. The Analysis of Model Stress-Strain Curve. Due to the factors of time, only five rock samples of physical test peak results are compared with the numerical simulation results, as shown in Figure 9.
Figure 9 shows the comparison of stress peak values under five different height-to-diameter ratios with those of physical tests under the same conditions. When the heightto-diameter ratio of the model is in the range of 1-2.5, the difference of stress peak value between numerical simulation and physical test is small, and the error range is less than $2.95 \%$. However, when the height-to-diameter ratio is equal to 2.5 , the difference of stress peak value between numerical simulation and physical test begins to enlarge. When the height-to-diameter ratio of the model is equal to 3.0, the difference of stress peak value between numerical simulation and physical test is the largest. The author believes that the reason for the large difference in the stress peak value is that the uniformity of the specimen in the physical test is difficult to control, and the model is greatly influenced by external factors when the loading is going on, such as the bonding method of the strain gauge and the effect of the loading time, resulting in the large dispersion of the stress peak value in the physical test. Therefore, the difference of stress peak value between numerical simulation and physical test is larger.

In addition, the stress data in Figures $4-8$ is extracted with the loading step and loading time, and the numerical simulation results are compared and analyzed, as shown in Figure 10.

Figure 10 shows that the stress peak value of the five models decreases gradually with the increase of height-todiameter ratio, and the failure time decreases gradually with the increase of load. When the height-to-diameter ratio is equal to 3.0, the failure peak value and the failure time of the model are the smallest and the shortest. In addition, by fitting the stress peak value values under five working conditions, it is found that, with the increase of the heightto-diameter ratio, the stress peak curve suddenly drops sharply from the approximate horizontal line at the initial height-to-diameter ratio of 1-2.5 at ratio of height to diameter equal to 3.0 , indicating that the model at this time is 


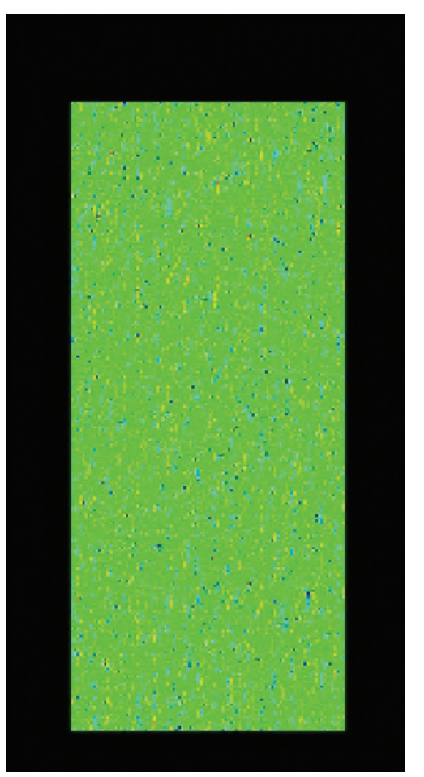

(a)

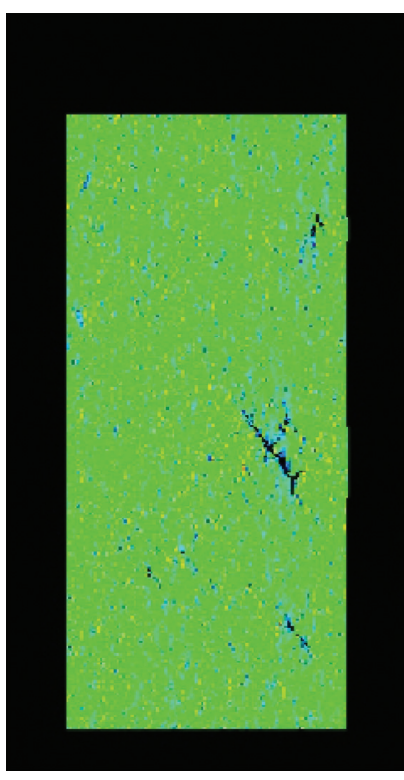

(b)

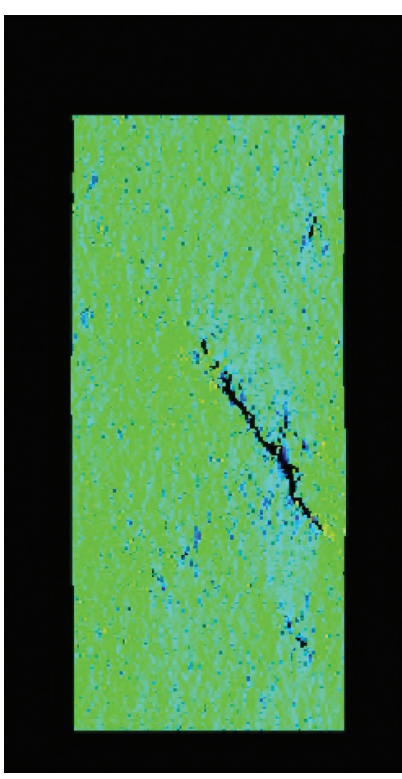

(c)

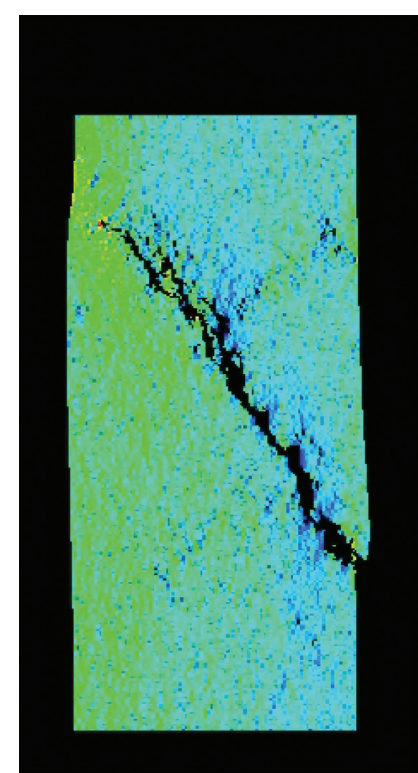

(d)

Figure 7: Macroscopic failure of rock mass at the height-to-diameter ratio of 2.5.

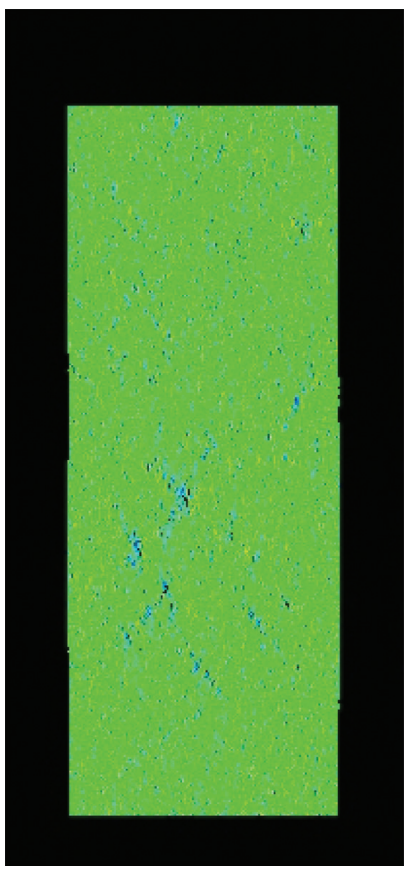

(a)

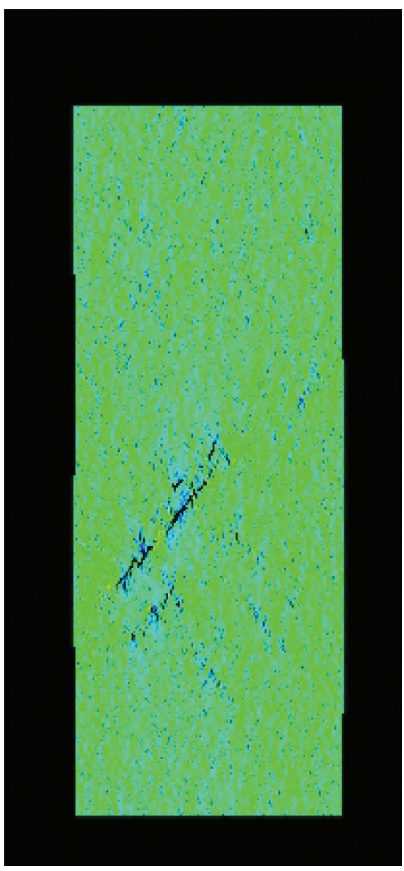

(b)

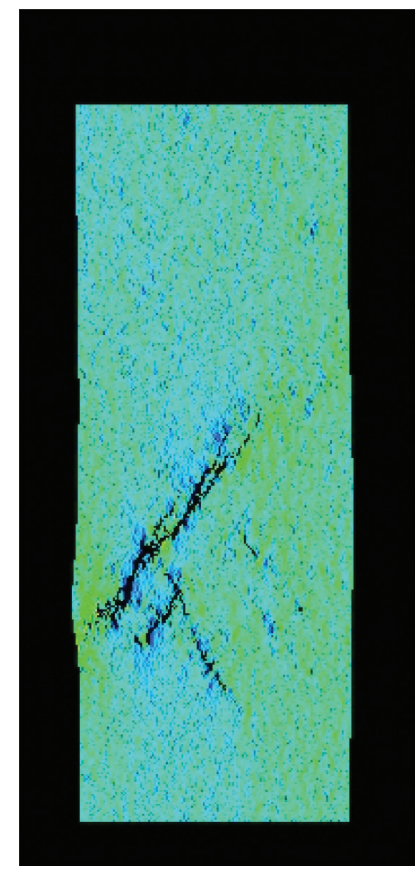

(c)

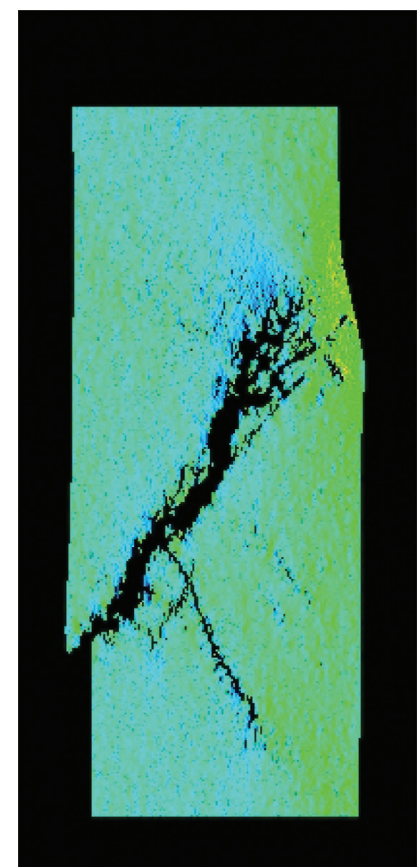

(d)

FIgURE 8: Macroscopic failure of rock mass at the height-to-diameter ratio of 3.

affected by its stability, resulting in a linear decline in the strength value. The height-to-diameter ratio of the standard specimen that also conforms to the model is suitable in the range of 1-2.

\subsection{The Expansion Simulation Results of Acoustic Emission of} the Model under Different Height-to-Diameter Ratios.
Figures $11(\mathrm{a}) \sim 11(\mathrm{~d})$ show the formation process of acoustic emission when the height-to-diameter ratio of the model is equal to 1.0. The red region represents tensile stress and the white represents compression-shear stress. With the loading step, due to the effect of compression and shear failure in the model, the white acoustic emission appears first and is dispersed throughout the entire model, as shown in Figure 12(b). However, in Figure 11(c), a large number of red areas appear 


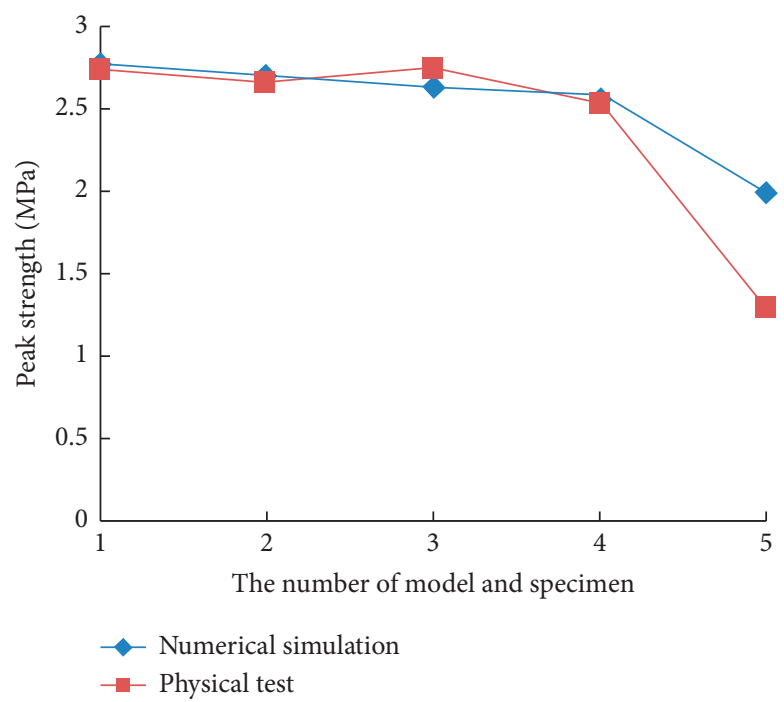

FIGURE 9: The comparison of physical test and stress peak value values of numerical simulation of five models.

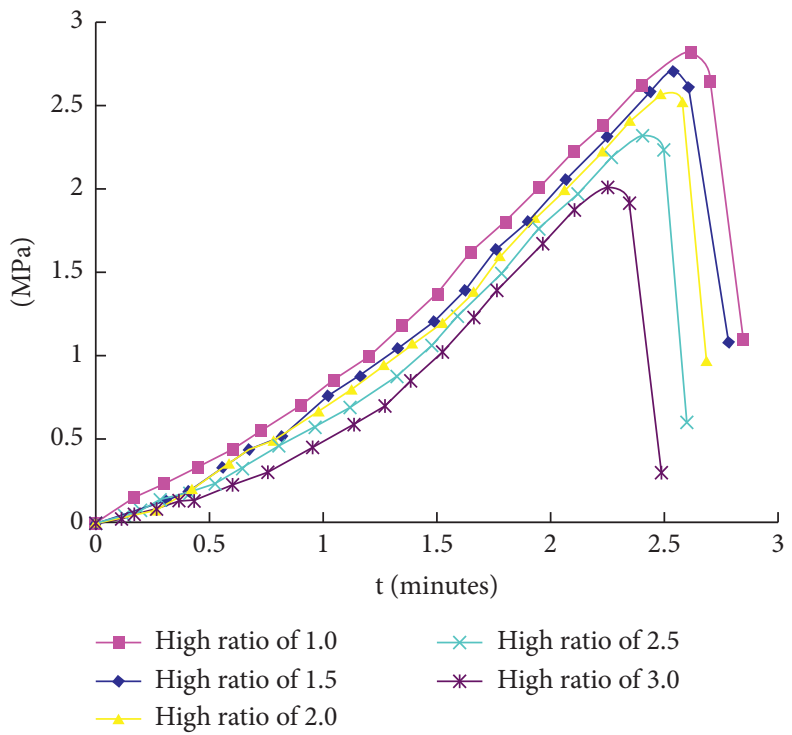

Figure 10: Stress-strain curves of five different height-to-diameter ratios.

along the $45^{\circ}$ direction of the model, indicating that the model produces tensile stress failure there. With the accumulation of acoustic emission energy, the red area in the model extends along the $45^{\circ}$ direction of the model and finally presents a consistent failure state with the macroscopic damage.

Figures $12(\mathrm{a}) \sim 12(\mathrm{~d})$ show the extension process of acoustic emission. The crack propagation of the model was shown by acoustic emission. The failure process of acoustic emission model: with displacement loading going on, the acoustic emission scattered and covered the whole model in the compaction stage of the model. The acoustic emission in this stage was generated absolutely by the compression-shear failure, and the representative color was white, indicating that the model was mainly subjected to compression-shear stress, as shown in Figure 12(b). However, with the increase of calculation steps, the red area in the model is more and more concentrated and linearly expanded, as shown in Figure 12(c), indicating that the failure of tensile stress occupies a dominant position in this area, and there is a small crack propagation to form the dominant crack in the model, which is consistent with the macroscopic failure state in Figure 5(d), as shown in Figure 12(d).

Figures 13(a) 13(d) show the acoustic emission crack propagation when the height-to-diameter ratio of the model is equal to 2. The failure process of acoustic emission model: the differences between the expansion mode of the red tensile stress area and that in Figure 8 is relatively small. With the increase of load, the acoustic emission in the white area generated by compression-shear failure is dispersed and filled with the whole model. However, with the increase of calculation steps, the red area generated by tensile stress gradually expands, and three dominant cracks are formed. 


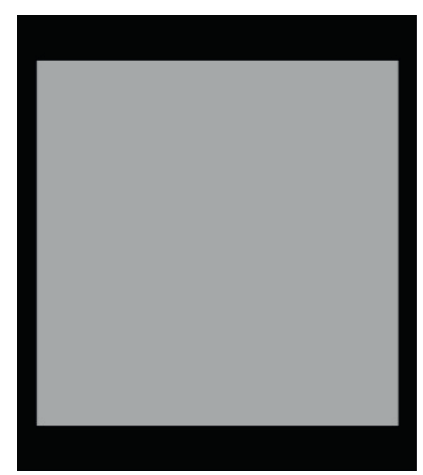

(a)

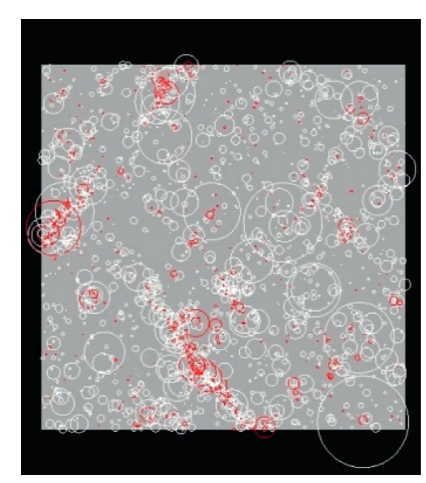

(b)

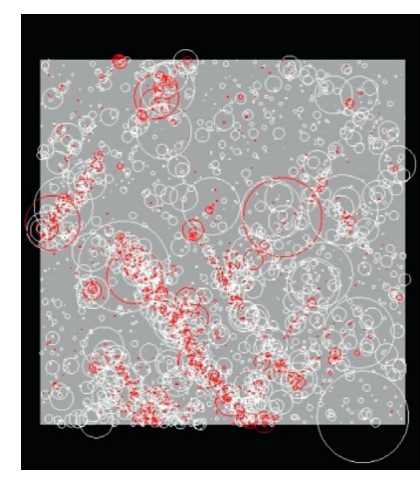

(c)

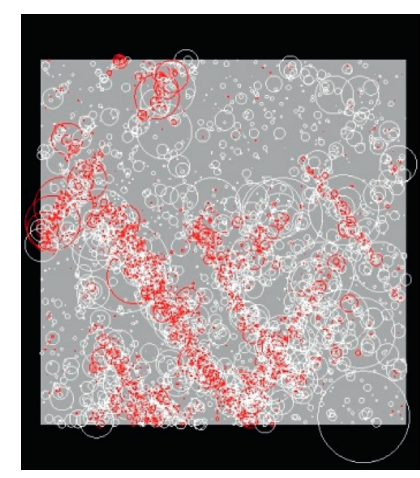

(d)

Figure 11: Acoustic emission of rock mass at ratio of height to diameter of 1 .

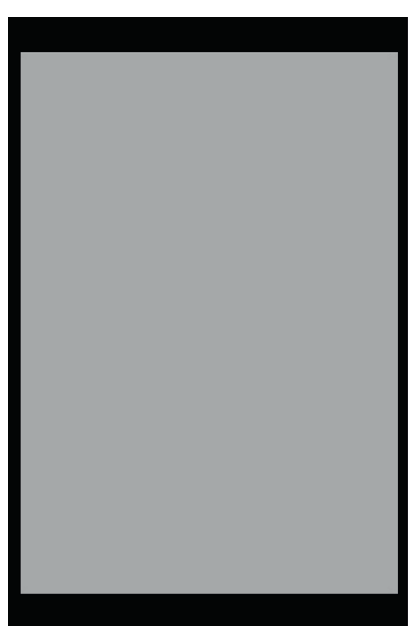

(a)

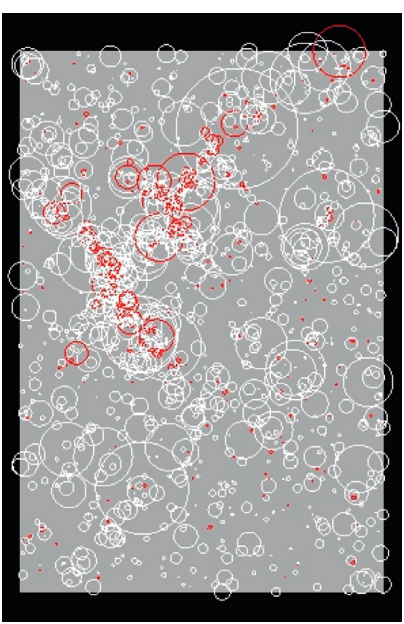

(b)

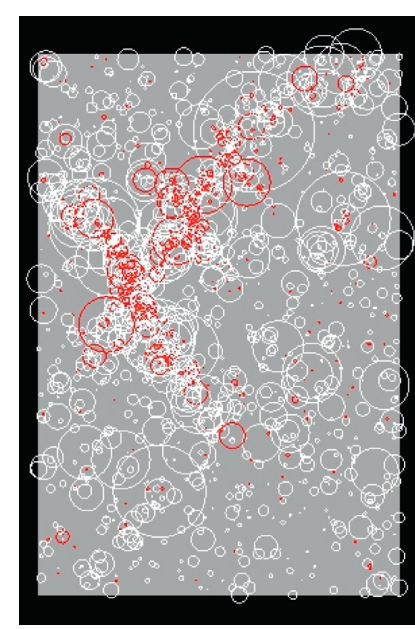

(c)

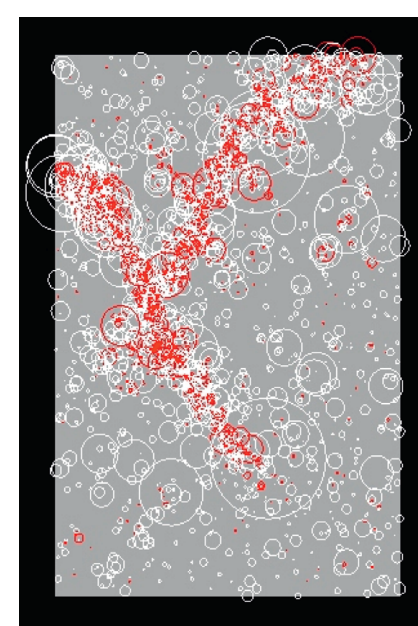

(d)

Figure 12: Acoustic emission of rock mass at ratio of height to diameter of 1.5.

The crack propagation direction is equal to $45^{\circ}$. At the later stage of the model calculation, the three dominant cracks expanded rapidly and finally showed consistency with the macroscopic failure state of Figure 6.

Figures $14(\mathrm{a}) \sim 14(\mathrm{~d})$ show the acoustic emission propagation process at ratio of height to diameter of 2.5 . In the initial model (a), two different colors of acoustic emission (b) appear with the loading. The white represents the compressive shear stress, and the red represents the tensile stress.

Acoustic emission expansion process of the model: due to the increase of the height of the model, and the fixedness of loading process, in the process of initial loading, acoustic emission has appeared and scattered over the entire model space, but the acoustic emission is still in the majority of white areas, indicating that the model is mainly affected by the compressive shear stress. With the increase of load and calculation step, the red area in the model gradually expands and concentrates in $45^{\circ}$ direction in the middle of the model. At the later stage of the model calculation, the red area of acoustic emission forms a dominant expansion and extends along the central $45^{\circ}$ direction; eventually, it is destroyed, releasing energy. The damage pattern is consistent with the macroscopic damage pattern in Figure 7.

Figures $15(\mathrm{a}) \sim 15(\mathrm{~d})$ show the acoustic emission extension process of the model. The acoustic emission propagation process of the model: with the loading, the model first produces the white acoustic emission, which is scattered and filled with the whole model by the compression-shear failure, and then the red acoustic emission generated by the tensile failure appears. With the loading, the acoustic emission of the tensile failure is accumulated in some positions, that is, in the stress concentration position. Subsequently, the acoustic emission of the tensile failure accumulates into a small crack shape and the surrounding area will also accumulate intensive decompression failure. As the loading continues to accumulate, the red acoustic emission gradually accumulates and expands. The crack rapidly expands; finally, it presents the consistent failure state with the macroscopic failure. 


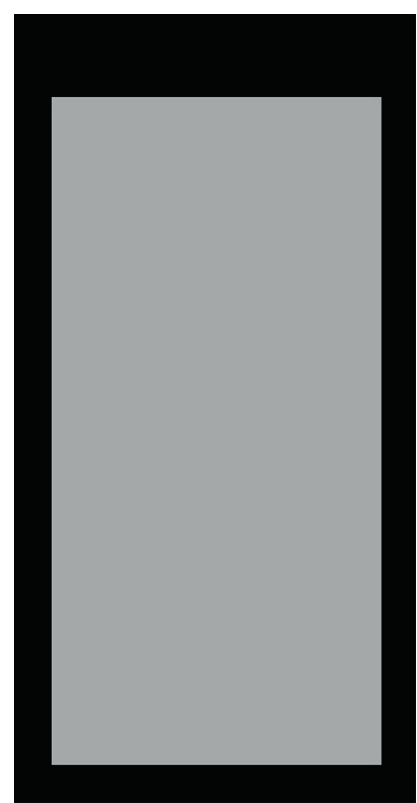

(a)

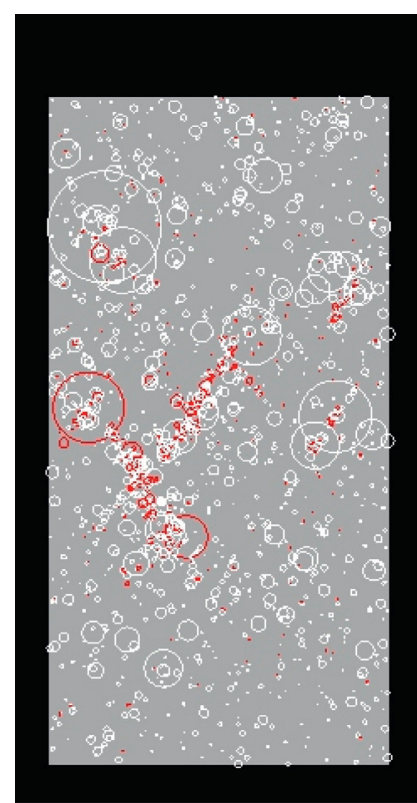

(b)

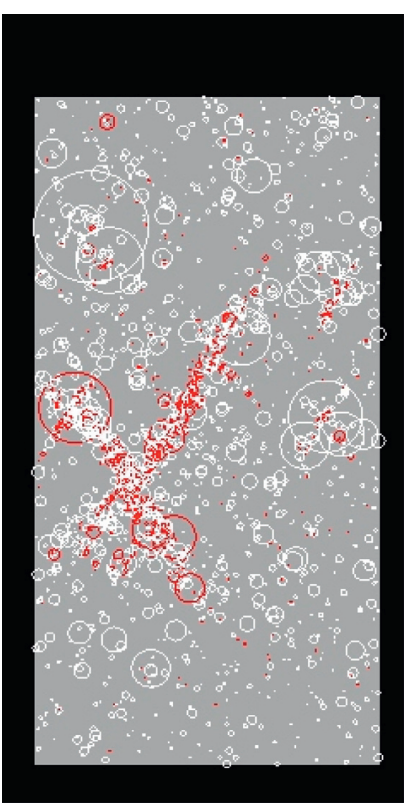

(c)

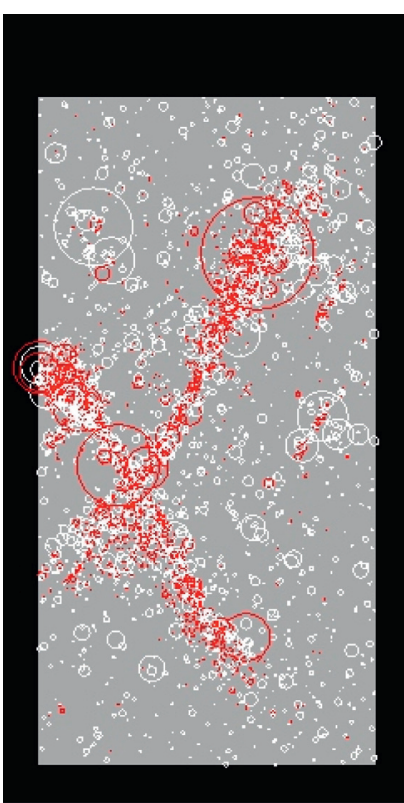

(d)

Figure 13: Acoustic emission of rock mass at ratio of height to diameter of 2 .

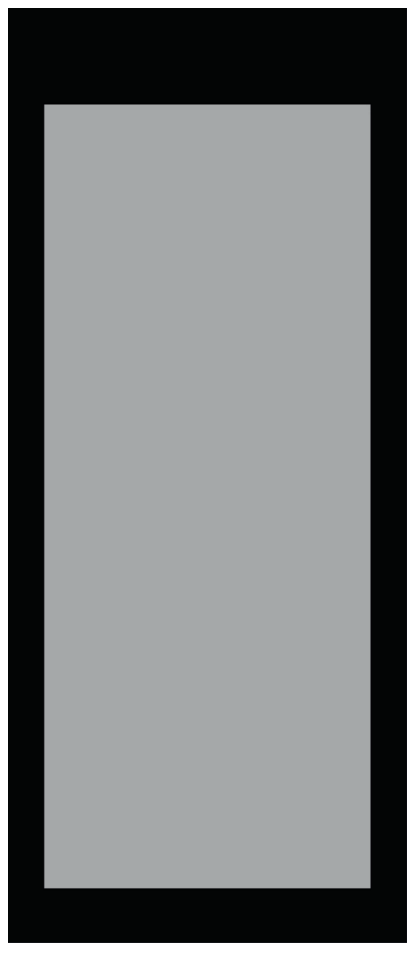

(a)

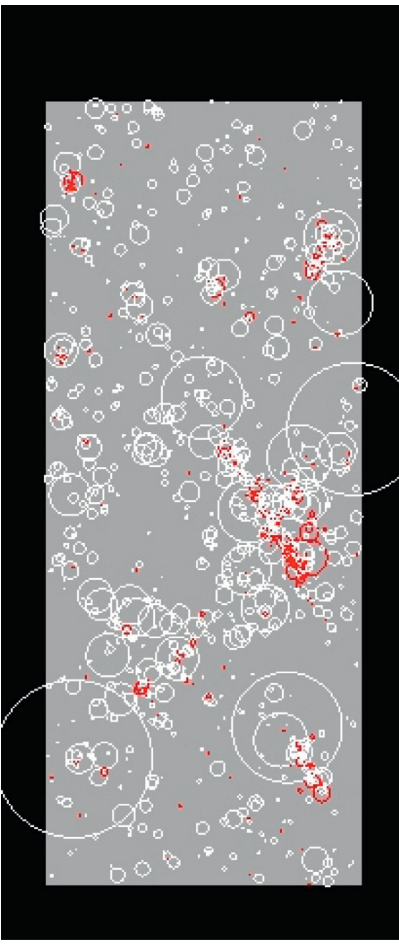

(b)

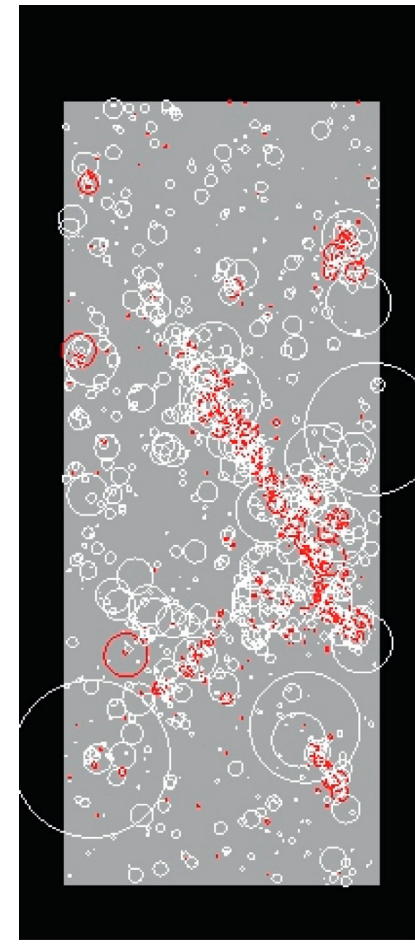

(c)

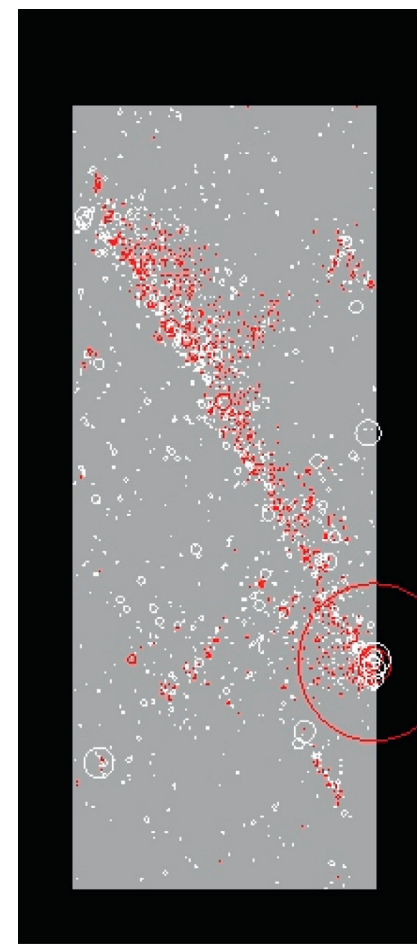

(d)

Figure 14: Acoustic emission propagation process of rock mass at ratio of height to diameter of 2.5 . 


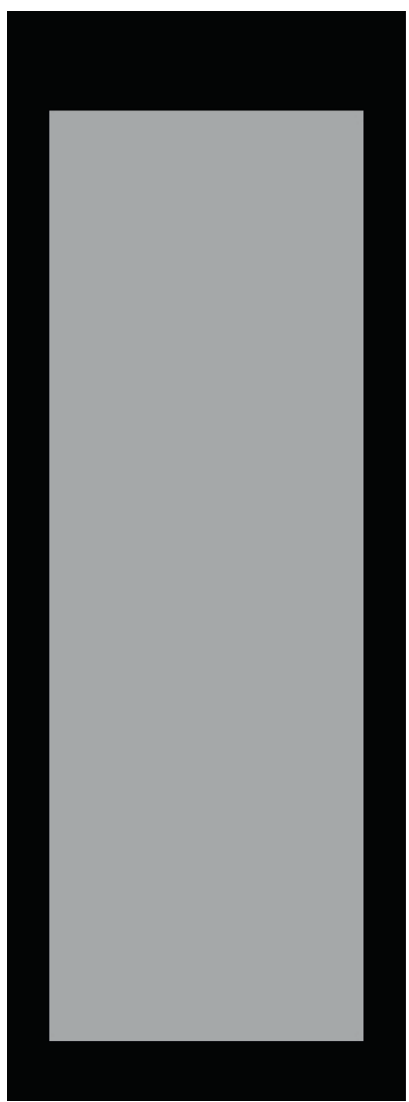

(a)

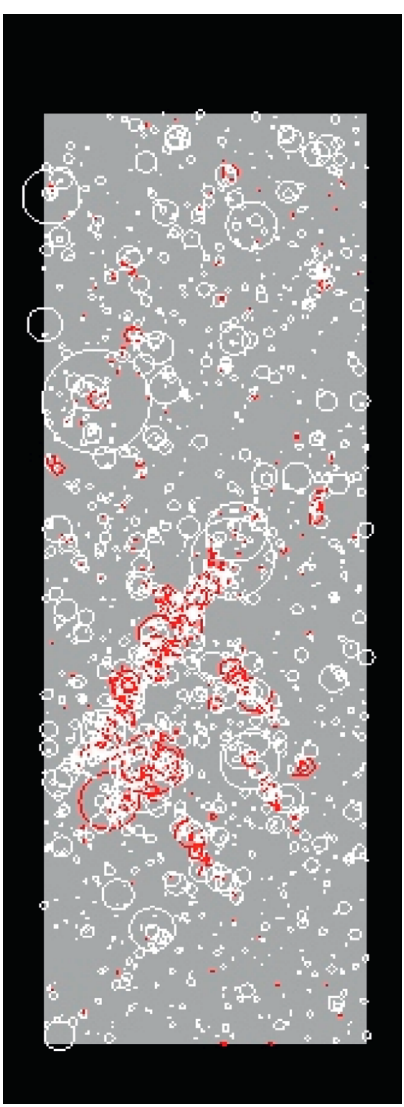

(b)

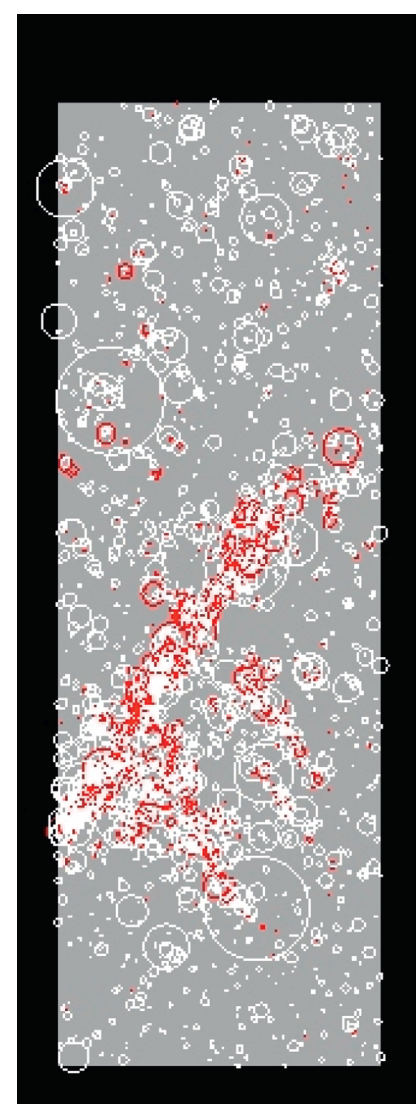

(c)

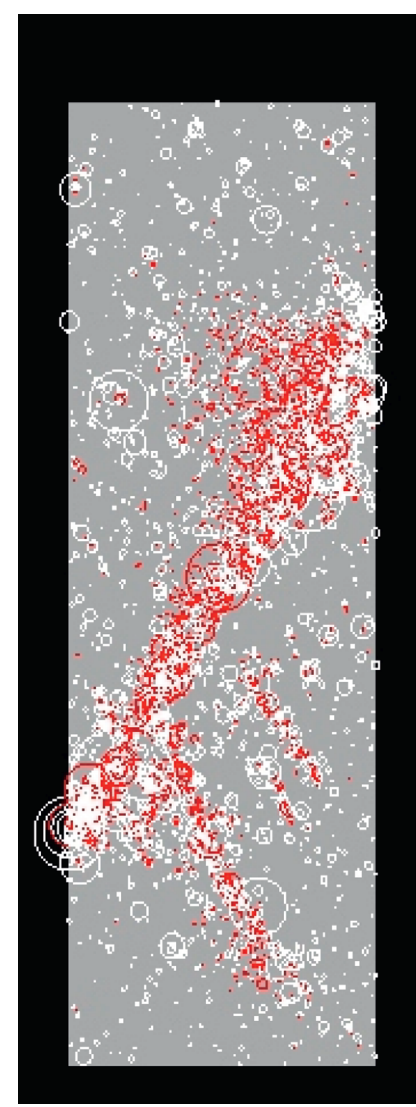

(d)

FIGURE 15: Acoustic emission propagation process of rock mass at ratio of height to diameter of 3.

\section{Conclusion}

In this paper, the advantages of RFPA (Rock Fracture Process Analysis) software are used to reproduce the physical experiment of rock through numerical simulation, which avoids the disadvantages of physical experiment. At the same time, the following conclusions are obtained through numerical simulation of model rocks with different sizes:

(1) Through the macroscopic damage of rock model and acoustic emission graphics, it is found that the results are consistent with the physical experiments results. Rocks gradually propagate from tiny cracks and form 1-2 dominant cracks. The direction and mode of crack propagation are the same as those of physical experiments. It shows that RFPA software has certain advantages in studying rock brittle failure.

(2) When the height-to-diameter ratio of the model is equal to 1 , the damage of the model is more complex, but the damage mode becomes simpler with the increase of the height-to-diameter ratio. The failure mode of stress concentration presents the form of axial failure. When the height-to-diameter ratio increases (1.5-2), other failure cracks will appear on the basis of axial splitting failure. As the height-todiameter ratio continues to increase (2.5), only shear failure occurs. When the height-to-diameter ratio reaches a relatively high level (3), there will be both axial splitting and other failure. When the length is too high, there will be axial splitting failure and some end failure.

(3) The selected rock stress parameters meet the requirements of physical experiments. The limit value of rock in brittle failure is determined by stress and energy diffusion curves. At the same time, it is also obtained that the failure mode changes from complex to simple with the increase of the height-to-diameter ratio of the model. However, when the height-to-diameter ratio of the model is equal to 3.0, due to the oversize height-todiameter ratio, the stress value and energy diffusion are not concentrated, indicating that the height of the model affects its stability and failure mode of the model.

\section{Data Availability}

The data used to support the findings of this study are available from the corresponding author upon request. 


\section{Conflicts of Interest}

The authors declare that there are no conflicts of interest.

\section{Acknowledgments}

This work was financially supported by Chinese National Key R\&D Project (No. 2016YFC0801402), Chinese National Natural Science Foundation Project (No. 51627804), and Inner Mongolia Natural Science Foundation Project (No. 2020MS05041).

\section{References}

[1] Z. C. Tian, C. A. Tang, Y. J. Liu, and Z. B. Li, "Numerical test on the rupture of straight-wall vault tunnel under different burial depths," China Minging Magazine, vol. 28, no. 2, pp. 91-96, 2019.

[2] Z. C. Tian, Y. J. Liu, W. C. Wang, and Yangduo, "Experimental study on influence relation between fire resistance and fire air quantity during mine fire," Mining Safety and Environmental Protection, vol. 42, no. 6, pp. 14-17, 2015.

[3] Z. C. Tian and Y. J. Liu, "Discrete element analysis on stability of gateway with bolt support retained along goaf," Coal Engineering, vol. 45, no. 3, pp. 71-73+77, 2013.

[4] Z. C. Tian, Y. J. Liu, and R. C. Wang, "Discussion on nonlinear dynamics division theory in mining applications," Modern Ming, vol. 27, no. 11, pp. 54-56, 2012.

[5] Z. C. Tian, C. P. Wang, and Y. J. Liu, "Analysis on the advantages of slicing mining in $4 \mathrm{~m}$ thick coal seam under specific conditions," Coal Mining Technology, vol. 16, no. 01, pp. 41-43, 2011.

[6] Z. C. Tian, Yanxin, and X. Q. Hou, "Research on the pressurized mine observe for the fully mechanized top coal caving mining face of impact danger coal bed in Xiagou Mine," Hebei Coal, no. 4, pp. 38-41, 2010.

[7] Z. C. Tian, Y. J. Liu, and C. P. Wang, "Application of defect structure in seam to prevent and control pressure bumping," Coal Engineering, no. 1, pp. 72-74, 2010.

[8] Yangliang, Y. J. Liu, and Z. C. Tian, C. A. Tang, J. H. Xue, C. R. Duan and Zhanghan, "Numerical test and application of gas pre-drainage in an extra-thick seam by using ground vertical boreholes," Rock and Soil Mechanics, vol. 40, no. 1, pp. 370-378, 2019.

[9] M. Zhang, Z. Liang, M. Gao, and N. Wu, "Numerical simulation of mechanical properties of rock specimens with cross-crack under different confining pressure," Chinese Journal of Underground Space and Engineering, vol. 16, no. 3, pp. 758-769, 2020.

[10] Y. D. Shou, X. P. Zhou, and Q. H. Qian, "Dynamic model of the zonal disintegration of rock surrounding a deep spherical cavity," International Journal of Geomechanics, vol. 17, no. 6, 2017.

[11] X.-T. Feng, S.-F. Pei, Q. Jiang, Y.-Y. Zhou, S.-J. Li, and Z.-B. Yao, "Deep fracturing of the hard rock surrounding a large underground cavern subjected to high geostress: in situ observation and mechanism analysis," Rock Mechanics and Rock Engineering, vol. 50, no. 8, pp. 2155-2175, 2017.

[12] Z. H. Zhang, "Pan YS Three-Dimensional similar material experimental study on zonal disintegration of deep tunnel failure," Journal of China Coal Society, vol. 40, no. 12, pp. 2780-2786, 2015.

[13] H. X. Chen, Numerical Research for Nonlinear Continuous Phase Transition Model of Zonal Disintegration of Rock Masses
Near Deep-Level Tunnels, Beijing University of Civil Engineering and Architecture, Beijing, China, 2016.

[14] X. Chen, N. Zhang, T. Ma, X. Niu, X. Liu, and T. Feng, "Energy-based forming and anchoring mechanism and criterion for zonal disintegration," Theoretical and Applied Fracture Mechanics, vol. 97, pp. 349-356, 2018.

[15] X. Chen, N. Zhang, and M. Zhang, "Energy-based forming mechanism and criterion for zonal disintegration," Journal of Testing and Evaluation, vol. 46, no. 5, pp. 1972-1982, 2018.

[16] J. A. Hudson and J. P. Harrison, "Testing techniques," Engineering Rock Mechanics, vol. 59, no. 2, pp. 173-191, 1997.

[17] Y. D. Shou, X. P. Zhou, and Q. H. Qian, “A critical condition of the zonal disintegration in deep rock masses: strain energy density approach," Theoretical and Applied Fracture Mechanics, vol. 97, pp. 322-332, 2018. 